\title{
Integrating national community-based health worker programmes into health systems: a systematic review identifying lessons learned from low-and middle-income countries
}

\author{
Joseph Mumba Zulu ${ }^{1,2^{*}}$, John Kinsman², Charles Michelo ${ }^{1}$ and Anna-Karin Hurtig ${ }^{2}$
}

\begin{abstract}
Background: Despite the development of national community-based health worker (CBHW) programmes in several low- and middle-income countries, their integration into health systems has not been optimal. Studies have been conducted to investigate the factors influencing the integration processes, but systematic reviews to provide a more comprehensive understanding are lacking.

Methods: We conducted a systematic review of published research to understand factors that may influence the integration of national CBHW programmes into health systems in low- and middle-income countries. To be included in the study, CBHW programmes should have been developed by the government and have standardised training, supervision and incentive structures. A conceptual framework on the integration of health innovations into health systems guided the review. We identified 3410 records, of which 36 were finally selected, and on which an analysis was conducted concerning the themes and pathways associated with different factors that may influence the integration process.
\end{abstract}

Results: Four programmes from Brazil, Ethiopia, India and Pakistan met the inclusion criteria. Different aspects of each of these programmes were integrated in different ways into their respective health systems. Factors that facilitated the integration process included the magnitude of countries' human resources for health problems and the associated discourses about how to address these problems; the perceived relative advantage of national CBHWs with regard to delivering health services over training and retaining highly skilled health workers; and the participation of some politicians and community members in programme processes, with the result that they viewed the programmes as legitimate, credible and relevant. Finally, integration of programmes within the existing health systems enhanced programme compatibility with the health systems' governance, financing and training functions. Factors that inhibited the integration process included a rapid scale-up process; resistance from other health workers; discrimination of CBHWs based on social, gender and economic status; ineffective incentive structures; inadequate infrastructure and supplies; and hierarchical and parallel communication structures.

Conclusions: CBHW programmes should design their scale-up strategy differently based on current contextual factors. Further, adoption of a stepwise approach to the scale-up and integration process may positively shape the integration process of CBHW programmes into health systems.

Keywords: National community-based health worker programmes, Integration, Health systems, Low- and middle-income countries

\footnotetext{
* Correspondence: josephmumbazulu@gmail.com

'Department of Public Health, School of Medicine, University of Zambia, P.O. Box 50110, Lusaka, Zambia

${ }^{2}$ Umeå International School of Public Health (UISPH), Umeå University, Umeå SE 90185, Sweden
} 


\section{Background}

Many low- and middle-income countries (LMICs) are facing human resources for health $(\mathrm{HRH})$ shortages [1-3]. According to the World Health Organization (WHO), more than 57 countries face critical health worker shortages, of which the majority (63\%) are in sub-Saharan Africa [1]. This shortage has affected the delivery of health services, and has also hindered progress towards attainment of the health-related Millennium Development Goals [4]. Causes of health workforce shortages include the inability of countries to train, retain and distribute health workers $[4,5]$. The involvement of community-based health workers (CBHWs) in primary health care is one strategy of addressing this gap [6].

The term CBHW is broad in scope and includes home-based care providers, community health workers, community-based treatment supporters, and traditional birth attendants [6].

Although some countries had already started engaging CBHWs in delivering primary health care before 1978, the number of countries increased further following the Declaration of Alma Ata in 1978 [2,6,7]. Article VII.7 of the Declaration recognised CBHWs as being vital to improving access to primary health care. The document stated that primary health care "relies, at local and referral levels, on health workers, including physicians, nurses, midwives, auxiliaries and community workers as applicable, as well as traditional practitioners as needed, suitably trained socially and technically to work as a health team and to respond to the expressed health needs of the community" [8], p 2.

However, there was a decline in interest in CBHW programmes in the late 1980s [9]. The reduced interest in the programmes resulted from the challenges that the first $\mathrm{CBHW}$ programmes experienced, and which reduced their programmatic effectiveness $[2,3,6]$. Specific difficulties included inadequate training, remuneration or incentives; limited supervision; deficient continuing education opportunities; inadequate supplies and medicines; and limited recognition or acceptance by other health workers $[2,3,7]$. Severe economic crisis faced by a number of countries also contributed to the reduced interest in CBHW programmes [9].

Nonetheless, in the early 1990s, renewed enthusiasm for CBHW programmes in LMICs emerged $[2,6]$. Several issues precipitated this interest, one of them being the increased advocacy by the WHO on the role of task shifting as a means of reducing the burden on overstretched health care systems [10]. Task shifting involves reviewing and delegating tasks away from clinical staff to non-clinical staff such as CBHWs, thereby enabling clinical staff to concentrate on their specific areas of expertise $[1,11,12]$. In addition, the demands imposed by the growing HIV epidemic, other infectious diseases, noncommunicable diseases, and general health coverage inequalities especially in rural communities, contributed to this renewed interest in community-based health care $[6,13]$. Further, an increase in the number of countries adopting decentralised health care policies and strategies, as well as community partnership policies, also contributed towards this renewed interest [2].

In an attempt to increase the potential for delivering positive health outcomes at a large scale, there was a move towards implementing national CBHW programmes $[6,10]$. Compared to small scale CBHW programmes (e.g. those implemented locally by Non-Governmental Organisations), Liu et al. [6] suggest that large-scale programmes have the potential to deliver positive health outcomes if appropriate attention is given to ensuring that they have strong management systems. In addition large scale CBHW programmes have the potential to successfully and rapidly recruit, train, and deploy a large cadre of CBHWs. Further, the specification of duties, standardisation of incentives, and the supervision as well as training which characterise most of these programmes should also facilitate CBHWs' ability to deliver good health services $[2,3,14]$.

In order to be effective and sustainable at national scale, Singh [15], p20 suggests that CBHWs should be "integrated into a nationwide primary health care system through recognition in national health care planning, regulation and implementation. Parallel systems for community health that are not integrated with the primary health care system risk weaker referral systems, supervision and support by facility based care providers, and policymaker buy-in to support supply chain and other systems components". However, many national CBHW programmes have faced considerable difficulties in the process of shifting from small-scale local projects to national CBHW schemes, with the lack of integration into the national health system being one of the major problems encountered [10]. Studies on some national CBHWs programmes have shown that their integration into their respective health systems has not been optimal $[6,16,17]$.

Although there has been an increase in the number of countries developing national CBHW programmes, there is limited systematic documentation on the factors that influence the integration process of CBHWs into health systems. Recent systematic reviews on CBHWs have focused more on their role in improving diseasespecific outcomes [18-21], as well as factors affecting the implementation of CBHW programmes for maternal and child health [2]. This paper intends to fill this knowledge gap by systematically assessing the factors that may influence the integration of these programmes into health systems in LMICs. We focus on the integration of existing $\mathrm{CBHW}$ programmes into official training, 
supervision and civil service systems, as well as the acceptability of the CBHWs to other health workers and the community. We expect that it will provide useful information that may guide integration processes in countries which are currently implementing similar programmes, as well as in those which intend to develop such programmes.

\section{Conceptual framework}

In analysing the factors that influence the integration process of national CBHWs into health systems, we have adopted a conceptual framework from Atun et al. [22]. According to this framework, integration of new health interventions into health system functions is influenced by the nature of the problem being addressed, the intervention, the adoption system, the health system characteristics, and the broad context (Figure 1). Drawing from this conceptual framework, we developed the following assumptions: First, the nature of the problem, such as the magnitude and discourse about the impact of and solutions to the HRH gap at national and global level, may influence actors' perspectives towards CBHW programmes, and these in turn may shape their integration process. Second, the attributes of the intervention, such as quality of service delivery by national CBHWs, may also influence the integration process. Integration may also be influenced by the level of the programme's compatibility with health system characteristics, such as resources and regulatory systems, as well as the broader context which includes, for example, demographic, economic, political and socio-cultural factors. Finally, the perspectives of national CBHW programmes by actors within the adopting system - who include policy makers, organisations, health workers, patients and communities - may either facilitate or inhabit the integration of CBHWs in health systems.

We selected this conceptual framework because it enables analysis of the interactions and interconnections between various factors influencing the integration

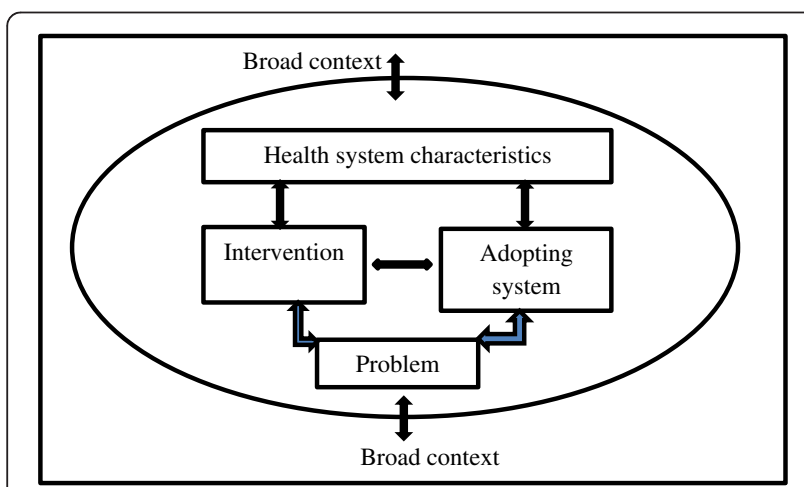

Figure 1 Conceptual framework for analysing integration process (adopted from Atun et al. [22]). process, thereby "allowing a systematic and holistic analysis of adoption and diffusion of health interventions in general" [22], p106.

We define integration as the process or extent and pattern of acceptability and adoption of the health intervention - in this case a CBHW programme - into critical functions of a health system [23-26]. These include the existing governance and leadership of an existing national health system as well as the shared goals and outcomes of existing health activities.

Meanwhile, the integration status of health interventions into health systems can take different forms, which include being fully, partially or not integrated with different elements of the health system [22-24]. Table 1 below shows how we have defined the terms "fully integrated", "partially integrated", and "not integrated" in this paper.

\section{Methods}

\section{Study design}

We carried out a systematic review to examine factors that may influence integration of national CBHW programmes, using Atun's [22] framework as a lens for analysis. A systematic review is a literature review focused on a research question or objective that tries to identify, appraise, select and synthesize quality research evidence relevant to the question or objective. In conducting the review, we were guided by the description by van der Knaap et al. [27] and Petrosino et al. [28] of the main aspects of a systematic review. These include formulation of a research question or objective; determination of the inclusion and exclusion criteria; description of the search for potential studies; screening of relevant studies that have been identified for eligibility according to the inclusion and exclusion criteria; determination of the quality of the selected studies; and production of data extracts, analysis and interpretation of the results.

\section{Search strategy}

We systematically searched the following websites for literature about national CBHW programmes between November 2013 and March, 2014: CINAHL, Medline, PubMed, ScienceDirect, Web of Science, BioMed Central, and the Cochrane Collaboration. For a programme to qualify to be included in the study, it had to meet the following criteria: the programme must have been formed and operated by the government; it should have training, supervision and incentive structures that are standardised and well-defined by the government; it should have been scaled nationally in or after the 1990s (the period when there was renewed enthusiasm for CBHW programmes in LMICs); and it should have been in operational for not less than five years. Only four programmes met the inclusion criteria: Accredited Social 
Table 1 Definition of integration status

\begin{tabular}{|c|c|c|c|}
\hline \multirow[b]{2}{*}{$\begin{array}{l}\text { Selected health systems } \\
\text { elements [24] }\end{array}$} & \multicolumn{3}{|l|}{ Integration status } \\
\hline & Full integration & Partial integration & Not integrated \\
\hline $\begin{array}{l}\text { Governance and } \\
\text { leadership }\end{array}$ & $\begin{array}{l}\text { Management and supervision of } \\
\text { CBHWs is conducted by other health } \\
\text { workers and institutions in the ministry } \\
\text { of health }\end{array}$ & $\begin{array}{l}\text { Management and supervision of CBHWs } \\
\text { is not completely conducted by other } \\
\text { health workers and institutions in the } \\
\text { ministry of health. Private stakeholders } \\
\text { such as NGOs are also involved }\end{array}$ & $\begin{array}{l}\text { CBHWs do not receive any } \\
\text { supervision from other health } \\
\text { workers and institutions in the } \\
\text { ministry of health }\end{array}$ \\
\hline Financial resources & $\begin{array}{l}\text { CBHWs are part of the civil service and } \\
\text { are paid standardised monthly salaries } \\
\text { by the government }\end{array}$ & $\begin{array}{l}\text { CBHWs are not part of civil service, } \\
\text { but receive standardised incentives } \\
\text { from the government }\end{array}$ & $\begin{array}{l}\text { CBHWs are not part of the civil } \\
\text { and do not have standardised } \\
\text { incentives from the government }\end{array}$ \\
\hline Human resources & $\begin{array}{l}\text { CBHWs receive standardised training } \\
\text { from the ministry of health and are } \\
\text { fully accepted as well as supported } \\
\text { by other health workers }\end{array}$ & $\begin{array}{l}\text { CBHWs receive standardised training } \\
\text { from the ministry of health but are not } \\
\text { fully accepted by some health workers }\end{array}$ & $\begin{array}{l}\text { CBHWs do not receive any form } \\
\text { of standardised training from the } \\
\text { ministry of health and are not } \\
\text { recognised by other health workers }\end{array}$ \\
\hline Service delivery & $\begin{array}{l}\text { CBHWs perform standardised tasks; } \\
\text { stakeholders recognise, accept and } \\
\text { utilise the services provided the CBHWs }\end{array}$ & $\begin{array}{l}\text { CBHWs perform standardised tasks; but } \\
\text { some stakeholders do not recognise, accept } \\
\text { and utilise the services provided the CBHWs }\end{array}$ & $\begin{array}{l}\text { CBHWs do not have standardised } \\
\text { tasks and duties }\end{array}$ \\
\hline Population & $\begin{array}{l}\text { CBHWs are recruited from the } \\
\text { community and are recognised and } \\
\text { accepted by the community }\end{array}$ & $\begin{array}{l}\text { CBHWs are recruited from the community } \\
\text { but are discriminated or not accepted by } \\
\text { part of the community }\end{array}$ & $\begin{array}{l}\text { Not all CBHWs are recruited and } \\
\text { work within their community and } \\
\text { most community members do } \\
\text { not recognise or accept CBHWs }\end{array}$ \\
\hline Outcomes and Goals & $\begin{array}{l}\text { CBHW services and duties are in line } \\
\text { with the national primary health care } \\
\text { system }\end{array}$ & $\begin{array}{l}\text { CBHW services and duties are not in line } \\
\text { with all of issues contained in the } \\
\text { national primary health care system }\end{array}$ & $\begin{array}{l}\text { CBHW duties and services are not } \\
\text { developed based on the national } \\
\text { primary health care system }\end{array}$ \\
\hline
\end{tabular}

Health Activists (ASHAs) in India, Community Health Agents (CHAs) in Brazil, Health Extension Workers (HEWs) in Ethiopia, and Lady Health Workers (LHWs) in Pakistan. Other large CBHWs that did not fit within this inclusion (for example the Bangladeshi programme, with about 80,000 CBHWs, and that was initiated and is operated by BRAC, a national Bangladeshi NGO) were excluded from the study.

Having selected the studies, we then searched the websites using specific programme names as follows: "The Community Health Agents in Brazil", or "Health Extension Workers in Ethiopia", or "Accredited Social Health Activists in India", or "The Lady Health Workers in Pakistan". Relevant literature was also identified by checking references of the articles and the websites of the WHO. A total of 3410 documents were identified, as reflected below in Table 2 .

\section{Study selection and quality assessment}

To ensure inclusion of relevant, high quality papers in this review, our inclusion criteria for documents comprised: peer-reviewed publications only; conducted in Brazil, Ethiopia, India and Pakistan; and including a focus on the integration of national CBWH programmes into health systems. We included papers with different study designs, including qualitative, mixed-methods, reviews, and programme evaluations.

With these inclusion criteria in mind, we then followed the Preferred Reporting Items for Systematic reviews and Meta-Analyses (PRISMA) guidelines by Moher et al. [29]

Table 2 Search outcomes for literature about national Community-Based Health Worker programmes

\begin{tabular}{|c|c|c|c|c|c|}
\hline \multirow[t]{2}{*}{ Data Source } & \multicolumn{5}{|c|}{ Countries } \\
\hline & Brazil & Ethiopia & India & Pakistan & Total \\
\hline The Cochrane Collaboration & & & & & 48 \\
\hline Web of science & 5 & 43 & 21 & 31 & 100 \\
\hline PubMed & 245 & 38 & 13 & 58 & 354 \\
\hline Medline & 8 & 40 & 35 & 44 & 127 \\
\hline Biomed Central & 194 & 56 & 45 & 39 & 334 \\
\hline CINAHL & 32 & 9 & 2 & 18 & 61 \\
\hline Science direct & 15 & 1115 & 33 & 350 & 1513 \\
\hline References and $\mathrm{WHO}$ websites & 426 & 243 & 37 & 167 & 873 \\
\hline Sub Totals & 925 & 1544 & 186 & 707 & \\
\hline
\end{tabular}


in selecting the studies. In accordance with the guidelines, we first excluded all duplicates (479) from the 3,410 search outcomes initially identified. Then we reviewed all the titles of the remaining 2,931 research papers and reports, of which we excluded 2,605, because they focused either on the wrong topic or region or both. We then remained with 326 outcomes. Subsequently we retrieved and assessed the abstracts of the 326 papers, of which we excluded 230 because they did not address the subject of integration of CBHWs into health systems. Finally, we retrieved 96 fulllength papers that were shortlisted after abstract review, in order to screen them in accordance with the inclusion criteria. At this stage, we also subjected the papers to the main elements of the Critical Appraisal Skills Programme (CASP) quality assessment that has been used to appraise studies, and especially those that use qualitative approaches [30]. This process resulted into the final 36 papers as shown in Figure 2.

The Critical Appraisal Skills Programme (CASP) quality assessment tool has been used in other syntheses of primarily qualitative evidence, such as Munro [31] and Glenton et al. [2]. Below is an overview of the quality criteria we used:

- Are the research questions or objectives clearly stated?

- Is the approach appropriate for the research question?

- Is the study context clearly described?

- Is the role of the researcher clearly described?

- Is the sampling method clearly described?

- Is the sampling strategy appropriate for the research question?

- Is the method of data collection clearly described?

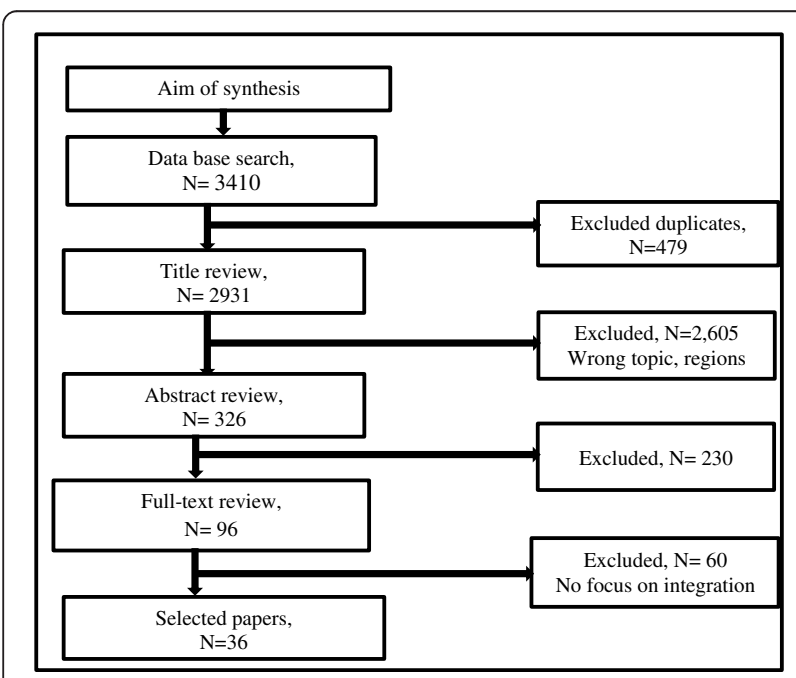

Figure 2 Search strategy and paper selection flow chart.
- Is the data collection method appropriate to the research question?

- Is the method of analysis clearly described?

- Is the analysis appropriate for the research question?

- Are the claims made supported by sufficient evidence?

\section{Data analysis}

We analysed and synthesised data in the 36 selected papers using a thematic analysis approach. This is "a method for identifying, analysing and reporting patterns (themes) within data. It organizes and describes data set in detail and goes further to interpret various aspects of the research topic" [32], p 79. Thematic analysis is one of the data analysis approaches recommended by the Cochrane Qualitative Review Methods Group [2,33]. The first step involved familiarisation with the included studies. During this process, themes regarding factors that could enable and/or inhibit the integration process were inductively developed, based on key components of the conceptual framework on integration of innovations into health systems [22]. The themes were then separately reviewed by all authors, after which final agreement on the themes (as given in Table 3) was achieved.

Having developed the themes, we described pathways on how and why factors relating to the nature of the problem, intervention, adoption system, health system characteristics, and the broad context may influence the integration of national CBHW programmes into health systems. This was necessary because the national $\mathrm{CBHW}$ programmes are introduced into health systems with dynamic and complex feedback loops, alongside non-linear relationships which extend beyond the health system and which are intricately linked to the context within which the system is embedded [22].

\section{Results}

In this section, we present our findings on the factors that influence the integration of national communitybased health worker (CBHW) programmes into health systems. The section has been organised around the major components of the conceptual framework on integration of health interventions into health systems, namely: characteristics of the problem, attributes of the intervention, the adoption system, and the health system characteristics. The fifth component of the framework, broad context, has been discussed within the other four components of the framework (the characteristics of the problem, attributes of the intervention, the adoption system, and the health system characteristics). The section starts by outlining the characteristics of the studies included in the review, followed by a description of the integration status of the four national CBHW programmes included in the paper into their respective health systems. 


\begin{tabular}{|c|c|}
\hline Integration condition & Factors influencing integration process \\
\hline \multirow{3}{*}{$\begin{array}{l}\text { Characteristics of } \\
\text { the problem }\end{array}$} & Human Resource for Health problem \\
\hline & $\begin{array}{l}\text { Discourse about Human Resource } \\
\text { for Health problem }\end{array}$ \\
\hline & Discourse about CBHWs \\
\hline \multirow{2}{*}{$\begin{array}{l}\text { Attributes of the } \\
\text { intervention }\end{array}$} & Service delivery \\
\hline & Performance of CBHWs \\
\hline \multirow[t]{2}{*}{ Adopting system } & $\begin{array}{l}\text { Politicians and professional health workers } \\
\text { programme perceptions }\end{array}$ \\
\hline & Community members programme perceptions \\
\hline \multirow{3}{*}{$\begin{array}{l}\text { Health system } \\
\text { characteristics }\end{array}$} & Training systems for $\mathrm{CBHWs}$ \\
\hline & Supervision process for $\mathrm{CBHW}$ \\
\hline & Incentive structure for CBHWs \\
\hline \multirow[t]{3}{*}{ Broad context } & Demographic factors \\
\hline & Economic factors \\
\hline & Socio-cultural factors \\
\hline
\end{tabular}

\section{Study Characteristics}

Thirty six (36) studies were included for the final review. Of these studies, thirteen (13) were reviews, ten (10) were mixed-methods studies, eight (7) were qualitative, while the remaining six (6) were programme evaluations. More detailed characteristics of the different studies, their aims and major findings, are provided in Table 4.

\section{Integration status of national community-based health worker programmes}

Below we introduce the four selected national CBHW programmes, and present a summary of the extent and pattern of their integration into their health systems. Overall there was considerable variation across and within the programmes with regard to their integration (Table 5).

With regard to operational status, the CHAs operate within the Brazil's Family Health Strategy [16], LHWs in the National Programme for Family Planning and Primary Health Care [17], HEWs in the Health Extension Programme $[3,26,40]$ and ASHAs in the Rural Health Mission programme [3]. More details about the national CBHW programmes (their roles, type of incentives and mode of supervision) are provided in Table 6.

\section{Factors influencing integration of national community-based health workers into health systems \\ Characteristics of the problem}

In the first of the major factors relating to the integration process that have been identified in the conceptual framework, we focus on how the characteristics of the problem (in this case the human resources for health crisis) may influence the acceptability and adoption of the intervention that has been designed to solve the problem (i.e. the national CBHW programme) within health systems.

\section{Human resources for health problem and discourse}

The HRH gap prevailing in most LMICs, including Brazil, Ethiopia, India and Pakistan, has precipitated increased attention and interest by policy makers and politicians in implementing and integrating national CBHW programmes into their national health systems $[2,3,6,20,44,45]$. The early discourse relating to the $\mathrm{HRH}$ gap in Brazil, Ethiopia, India and Pakistan focused mainly on expanding health facilities and training highly skilled health workers [2,3]. However, these approaches proved difficult due to limited capacity to train and retain highly skilled health workers in the countries [3]. This limited capacity generated increased interest by international and national institutions in continuing discussions about the effects of, as well as potential solutions to the health workforce crisis. As the discourse evolved, there was recognition that there may not be enough professional health workers available within an acceptable time frame [3]. On this basis, the discourse about addressing the HRH gap shifted towards developing national $\mathrm{CBHW}$ programmes.

Further, increased discussion and advocacy by actors within the global context, such as the WHO, also motivated countries to implement CBHW programmes [2]. For example "being signatory to Alma Ata declaration, the Government of Pakistan took concrete steps in collaboration with WHO, and launched its first nation-wide CBHW programme known as Lady Health Worker's Programme in 1994" [17], p 3. In general, the increased demand for primary health care, as well as the disease burden in Brazil, Ethiopia, Pakistan and India also facilitated the acceptance of national CBHWs into the health systems [6,35,38,41,46-48].

More recently, "the growing focus on the human resource crisis in health care has re-energised debates regarding the roles that CBHWs may play in extending services to 'hard to reach' groups and areas, and in substituting for health professionals for a range of tasks" [2], $\mathrm{p} 4$. In this context, national CBHWs are thought to play an important role in achieving demonstrable health benefits that are directly related to the health-related Millennium Development Goals, namely reducing child malnutrition, reducing child and maternal mortality, and controlling HIV/AIDS, tuberculosis (TB) and malaria $[2,3]$. Such positive discussion and views about the possible roles of CBHWs in efforts towards achieving the Millennium Development Goals has positively influenced the integration process of national CBHWs into governance and health service delivery [2,6,19,20,48].

In addition, the WHO has continued, as part of efforts to address the global health worker shortage, to recommend 
Table 4 Study characteristics

\begin{tabular}{|c|c|c|c|c|c|c|}
\hline No & $\begin{array}{l}1^{\text {st }} \text { Author/Year } \\
\text { [Citations] }\end{array}$ & Country & $\begin{array}{l}\text { Study type/ } \\
\text { design }\end{array}$ & $\begin{array}{l}\text { Type of } \\
\text { CBHWs }\end{array}$ & Aim & Key issues/findings \\
\hline \multicolumn{7}{|c|}{ Brazil specific studies } \\
\hline 1 & Svitone [46] & Brazil & Review & $\mathrm{CHAs}$ & $\begin{array}{l}\text { To document primary health care lessons } \\
\text { from the Northeast of Brazil following } \\
\text { the implementation of CHAs Programme }\end{array}$ & $\begin{array}{l}\text { Comprehensive information available, } \\
\text { a decline in infant mortality, a rise in } \\
\text { immunization, and timely interventions } \\
\text { in times of crisis }\end{array}$ \\
\hline 2 & Macinko [35] & Brazil & $\begin{array}{l}\text { Program } \\
\text { Evaluation }\end{array}$ & $\mathrm{CHAs}$ & $\begin{array}{l}\text { To assess the effects of an integrated } \\
\text { community-based primary care programme } \\
\text { on microregional variations in infant mortality } \\
\text { (IMR), neonatal mortality, and post-neonatal } \\
\text { mortality rates from } 1999 \text { to } 2004\end{array}$ & $\begin{array}{l}\text { Results show that infant mortality rate } \\
\text { declined about } 13 \text { percent from } 1999 \text { to } \\
\text { 2004, while Family Health Program } \\
\text { coverage increased from an average of } \\
\text { about } 14 \text { to nearly } 60 \text { percent }\end{array}$ \\
\hline 3 & Aquino [16] & Brazil & $\begin{array}{l}\text { Program } \\
\text { Evaluation }\end{array}$ & CHAs & $\begin{array}{l}\text { To evaluate the effects of the Family } \\
\text { Health Programme (FHP) on infant } \\
\text { mortality at a municipality level }\end{array}$ & $\begin{array}{l}\text { The FHP had an important effect on } \\
\text { reducing the infant mortality rate in } \\
\text { Brazilian municipalities from } 1996 \text { to } \\
\text { 2004. The FHP may also contribute } \\
\text { toward reducing health inequalities }\end{array}$ \\
\hline 4 & Zanchetta [40] & Brazil & $\begin{array}{l}\text { Mixed } \\
\text { methods }\end{array}$ & CHAs & $\begin{array}{l}\text { To assessing the effectiveness of CHAs' } \\
\text { actions in situations of social vulnerability }\end{array}$ & $\begin{array}{l}\text { Barriers to CHAs' effectiveness included } \\
\text { professional powerlessness, communication } \\
\text { gaps, fragmented teamwork, organizational } \\
\text { and structural barriers }\end{array}$ \\
\hline
\end{tabular}

\section{Ethiopia Specific studies}

5 Girma [40]

Ethiopia

Review

HEWS

$6 \quad$ Negusse [26]

Ethiopia Mixed

methods

7

Teklehaimanot [41] Ethiopia Qualitative HEWs
Admassie [47]

Ethiopia

Program Evaluation

HEWs

10

11 Medhanyie [58]

HEWs

Mixed methods

12

\section{Ethiopia}

Program Evaluation

13 Birhanu [61]

Ethiopia

Mixed methods

HEWs HEWs

HEWS (Case study)

14 Teklehaimanot [42] Ethiopia Qualitative HEWs (Case study)
To understand implications of strategies for human resource development (HRD) by 2015

To document the initial community perspectives on the Health Service Extension Programme in Welkait

To assess the working conditions of HEWs in Ethiopia and their job satisfaction

To evaluate the short-term and intermediate-term impacts of the HEW programme on child and maternal health indicators in the programme villages

To explore Ethiopia's progress toward achieving MDG 5 through the Health Extension Programme

To examine conditions that may affect the quality of HEWs training in Ethiopia

To investigate the Knowledge and performance of the HEWs on antenatal and delivery care as well as the barriers and facilitators to service provision

To assess the role of HEWs in improving utilization of maternal health services in rural areas in Ethiopia

To assess mothers' experiences and satisfaction with health extension service

The process to develop policy and strategy for managing human resource for health has been started

HEWs are helpful, HEWs are more preferred over TBAs, HEWs provide good health services. Limitations: less visits, poor knowledge on major communicable diseases

Health indicators have improved, performance in skilled delivery and postnatal care not satisfactory. Limited quality of service, utilization rate, access, referrals and programme evaluation

The proportion of children and women using insecticide-treated bednets for malaria protection are significantly larger in programme villages than in non-programme villages

Achieving the set targets is a daunting task despite reaching the physical targets of two health extension workers per health post

Training inadequacies

Poor knowledge of HEWs, poorly equipped health posts, and poor referral systems affected acceptability of services

Better utilization of family planning, antenatal care etc. Limited contribution to health facility delivery, postnatal check-up etc.

Most mothers had good relationships, were satisfied with and had positive attitude towards HEWs. Programme was however criticized for not including curative services and the less attention given to static services at health post

To describe the strategies, human resource developments, service delivery modalities, progress in service coverage, and the challenges in implementing the HEP
Health system reformed to create a platform for integration/ institutionalization of the HEP with appropriate human capacity, infrastructure, and management structures 
Table 4 Study characteristics (Continued)

\begin{tabular}{|c|c|c|c|c|}
\hline \multicolumn{5}{|c|}{ India specific studies } \\
\hline 15 & Scott [49] & India & $\begin{array}{l}\text { Qualitative } \\
\text { (Case study) }\end{array}$ & ASHAS \\
\hline 16 & Gopalan [60] & India & $\begin{array}{l}\text { Mixed- } \\
\text { methods }\end{array}$ & ASHAS \\
\hline 17 & Kumar [43] & India & $\begin{array}{l}\text { Program } \\
\text { Evaluation }\end{array}$ & ASHAS \\
\hline 18 & Shrivastava [54] & India & $\begin{array}{l}\text { Mixed- } \\
\text { methods }\end{array}$ & ASHAs \\
\hline
\end{tabular}

To investigate the contextual features

hindering the ASHAs' capacity to increase quantitative health outcomes and act as cultural mediators and agents of social change

To examine the performance motivation of community health workers (CHWs) and its determinants on India's Accredited Social Health Activist (ASHA) programme

To study the factors influencing the work performance of ASHAs in community

To evaluate the knowledge, attitudes and practices of ASHA workers in relation to child health

SHAs limited by: (1) the outcome-based remuneration structure; (2) poor institutional support; (3) the rigid hierarchical structure of the health system; and (4) a dearth of participation at the community level

Performance motivation mainly influenced by the individual and the community level factors, while the health system factors scored the least

Limitations included less knowledge, caste system, limited incentive practices and inadequate incentives

Gaps still exists in ASHAs' knowledge regarding various aspects of child health morbidity

\section{Pakistan specific studies}

19 Afsar [50]

Pakistan

Program

Evaluation

20 Afsar [51] Pakista

Qualitativ

LHWS

21 Douthwaite [38] Pakistan

Mixed methods

22 Haq [57]

Pakistan

Mixed methods

23 Haq [39]

Pakistan

Qualitative

LHWs

24 Hafeez [37]

Pakistan

Mixed

methods

LHWS

25

26 Wazir [17]

Pakistan

Mixedmethods

LHWS

Review

LHWs
To estimate the proportion of patient referral and to identify the factors associated with unsuccessful referral in Karachi, Pakistan

To assess the strengths and weakness of the National Programme for Family Planning and Primary Health Care from the LHWs' perspectives

To evaluate the Lady Health Worker programme

To evaluate job stress among community health workers in Pakistan

To document the perceptions of LHWs on their knowledge and communication needs, image building

To review the LHW programme and explore various aspects of the process to extract tangible implications for other similar situations

To explore the impact of socio-cultural factors on LHWs' home-visit rates

To conduct a SWOT analysis of the National Program for Family Planning and Primary Health Care in Pakistan

Limited communication and counselling skills of LHWs contributed to significant proportion of unsuccessful referrals

Strengths: Some community members accepting LHWs. Weaknesses: contractual job, low salaries, irregular payment, no career development and poor logistical support

The LHWP has succeeded in increasing modern contraceptive use among rural women

Challenges: stress, low socio-economic status, long distances; inadequate, medical supplies, stipends, communication skills, lack of career structure

Many respondents described their communication skills as moderately sufficient. Knowledge on emerging health issues was insufficient

Improved community links with first leve care facilities, earned community trust. Limitations: poor support from sub-optima health facilities, financial constraints and political interference

Performance is constrained by both gender and biradari/caste-based hierarchies.

Strengths: comprehensive planning, implementation and supervision mechanisms, selection and recruitment processes. Weaknesses: slow progress, poor program integration, job insecurity and delayed salaries

\begin{tabular}{|c|c|c|c|c|}
\hline \multicolumn{5}{|c|}{ Studies focusing on more than one country } \\
\hline 27 & Hermann [44] & $\begin{array}{l}\text { Ethiopia } \\
\text { and others }\end{array}$ & Review & HEWs \\
\hline 28 & Celletti [34] & $\begin{array}{l}\text { Brazil, } \\
\text { Ethiopia, } \\
\text { etc. }\end{array}$ & Qualitative & CHAs HEW \\
\hline
\end{tabular}

etc.

To investigate whether present CBHW programmes for ART are taking into account the lessons learnt from pas experiences and analyse the extent to which they are seizing the new ART-specific opportunities

To evaluate the contribution of CHWs with a focus on identifying the critical elements of an enabling environment that can ensure that they provide quality services in a manner that is sustainable
Adequate remuneration key to $\mathrm{CBHW}$ retention. Sufficient attention to be given to supervision, continuous training and health systems strengthening

Important requirements include adequate systems integration, political commitment; good planning, definition of scope of practice, selection, educational issues, career path, registration, licensure and certification; recruitment and deployment; adequate remuneration, supervision; referral system; supplies 
Table 4 Study characteristics (Continued)

\begin{tabular}{|c|c|c|c|c|c|c|}
\hline 29 & Kane [19] & $\begin{array}{l}\text { Brazil, } \\
\text { Ethiopia, } \\
\text { India, } \\
\text { Pakistan, } \\
\text { etc. }\end{array}$ & $\begin{array}{l}\text { Realist } \\
\text { synthesis } \\
\text { (Review) }\end{array}$ & $\begin{array}{l}\text { CHAs, HEWs, } \\
\text { ASHAs, LHWs }\end{array}$ & $\begin{array}{l}\text { To explore if randomised controlled } \\
\text { trails could yield insight into the working } \\
\text { of the interventions, when examined from } \\
\text { a different perspective, a realist perspective }\end{array}$ & $\begin{array}{l}\text { Positive mechanisms: anticipation of being } \\
\text { valued; perceived improved social status; } \\
\text { sense of relatedness with the health } \\
\text { system; increased self esteem, sense of } \\
\text { self efficacy, enactive mastery of tasks; } \\
\text { sense of credibility, legitimacy }\end{array}$ \\
\hline 30 & Lewin [20] & $\begin{array}{l}\text { Brazil, } \\
\text { Ethiopia, } \\
\text { India, } \\
\text { Pakistan, } \\
\text { etc. }\end{array}$ & $\begin{array}{l}\text { Systematic } \\
\text { review }\end{array}$ & $\begin{array}{l}\text { CHAs, HEWs, } \\
\text { ASHAs, LHWs }\end{array}$ & $\begin{array}{l}\text { To assess the effects of LHW interventions } \\
\text { in primary and community health care on } \\
\text { maternal and child health and the } \\
\text { management of infectious diseases }\end{array}$ & $\begin{array}{l}\text { LHWs provide promising benefits in } \\
\text { promoting immunisation uptake and } \\
\text { breastfeeding, improving TB treatment } \\
\text { outcomes, and reducing child morbidity } \\
\text { and mortality when compared to usual care }\end{array}$ \\
\hline 31 & Liu [6] & $\begin{array}{l}\text { Brazil, } \\
\text { Ethiopia, } \\
\text { India, } \\
\text { Pakistan, } \\
\text { etc. }\end{array}$ & Review & $\begin{array}{l}\text { CHAs, HEWs, } \\
\text { ASHAs, LHWs }\end{array}$ & $\begin{array}{l}\text { To explore CBHW programmes that have } \\
\text { been deployed at national scale, as well } \\
\text { as scalable innovations found in successful } \\
\text { nongovernmental organization-run } \\
\text { community health worker programmes }\end{array}$ & $\begin{array}{l}\text { Ability by national CBWH programmes to } \\
\text { reach scale is impressive, but quality and } \\
\text { management challenging. If well managed } \\
\text { programmes integrated into a well- } \\
\text { functioning primary healthcare system } \\
\text { can promote care and act as an } \\
\text { effective link }\end{array}$ \\
\hline 32 & Wouters [48] & $\begin{array}{l}\text { Ethiopia } \\
\text { and others }\end{array}$ & $\begin{array}{l}\text { Synthetic } \\
\text { review }\end{array}$ & HEWs & $\begin{array}{l}\text { To review the impact of community-based } \\
\text { support services on ART delivery and } \\
\text { outcomes in resource-limited countries }\end{array}$ & $\begin{array}{l}\text { CBHWs are not necessarily cheap or easy, } \\
\text { a good investment to improve coverage } \\
\text { of communities in need of health services }\end{array}$ \\
\hline 33 & Jaskiewicz [56] & $\begin{array}{l}\text { Ethiopia } \\
\text { Pakistan } \\
\text { and others }\end{array}$ & Review & HEWs LHWS & $\begin{array}{l}\text { To review the influence of work } \\
\text { environment in increasing community } \\
\text { health worker productivity and } \\
\text { effectiveness }\end{array}$ & $\begin{array}{l}\text { Essential elements for improving productivity: } \\
\text { defined workload, supportive supervision, } \\
\text { supplies and equipment, and respect from } \\
\text { the community and the health system }\end{array}$ \\
\hline 34 & Balabanova [45] & $\begin{array}{l}\text { Ethiopia, } \\
\text { etc. }\end{array}$ & Review & HEWs, etc. & $\begin{array}{l}\text { To discuss why some countries or regions } \\
\text { achieve better health and social outcomes } \\
\text { than others at a similar level of income } \\
\text { and to show the role of political will } \\
\text { and socially progressive policies }\end{array}$ & $\begin{array}{l}\text { Attributes of success included good } \\
\text { governance, political commitment, effective } \\
\text { bureaucracies, ability to innovate and adapt } \\
\text { to resource limitations, the capacity to } \\
\text { respond to population needs and build } \\
\text { resilience into health systems to face } \\
\text { challenges. Transport infrastructure, female } \\
\text { empowerment, and education also played } \\
\text { a part }\end{array}$ \\
\hline 35 & Glenton [2] & $\begin{array}{l}\text { Brazil, } \\
\text { Ethiopia, } \\
\text { India, } \\
\text { Pakistan, } \\
\text { etc. }\end{array}$ & $\begin{array}{l}\text { Systematic } \\
\text { review }\end{array}$ & $\begin{array}{l}\text { CHAs, HEWs, } \\
\text { ASHAs, LHWs }\end{array}$ & $\begin{array}{l}\text { To explore factors affecting the } \\
\text { implementation of LHW programmes } \\
\text { for maternal and child health }\end{array}$ & $\begin{array}{l}\text { Barriers and facilitators were mainly } \\
\text { tied to programme acceptability, } \\
\text { appropriateness and credibility; and } \\
\text { health system constraints }\end{array}$ \\
\hline 36 & Perry [3] & $\begin{array}{l}\text { Brazil and } \\
\text { others }\end{array}$ & Review & $\mathrm{CHAs}$ & $\begin{array}{l}\text { To summarize the history, recent evolution, } \\
\text { and current evidence of the effectiveness } \\
\text { of CHWs around the world }\end{array}$ & $\begin{array}{l}\text { CBHWs promote healthy behaviors, } \\
\text { extend reach of health systems, help } \\
\text { address health workforce resources } \\
\text { shortage, and reduce health disparities }\end{array}$ \\
\hline
\end{tabular}

Table 5 Integration status of national CBHW programmes

\begin{tabular}{|c|c|c|c|c|}
\hline \multirow[b]{2}{*}{$\begin{array}{l}\text { Health systems } \\
\text { elements [24] }\end{array}$} & \multicolumn{4}{|c|}{ Name of $\mathrm{CBHW}$ programme and integration status } \\
\hline & CHA-Brazil $[3,16,31,35,36]$ & LHWs-Pakistan $[3,17,37-39]$ & HEWs -Ethiopia $[3,26,34,40-42]$ & ASHAs- India $[3,6,43]$ \\
\hline Governance and leadership & Full integration & Full integration & Full integration & Partial integration \\
\hline Financial resources & Full integration & Full integration & Full integration & Partial integration \\
\hline Human resources & Partial integration & Partial integration & Full integration & Partial integration \\
\hline Service delivery & Partial integration & Partial integration & Partial integration & Partial integration \\
\hline Population & Full integration & Partial integration & Partial integration & Partial integration \\
\hline Outcomes & Full integration & Full integration & Full integration & Full integration \\
\hline Goals & Full integration & Full integration & Full integration & Full integration \\
\hline
\end{tabular}


Table 6 Summary of national scale programmes

\begin{tabular}{|c|c|c|c|c|}
\hline Country & CBHW programme & Roles & Incentives & Supervision \\
\hline \multirow[t]{3}{*}{ Brazil } & $\begin{array}{l}\text { Community Health Assistants } \\
\text { (CHAs) }\end{array}$ & \multirow{3}{*}{$\begin{array}{l}\text { Promoting breastfeeding as well as } \\
\text { providing prenatal, child care, } \\
\text { immunizations, screening and } \\
\text { treatment of infectious diseases services }\end{array}$} & \multirow[t]{3}{*}{$\begin{array}{l}\text { From } \$ 100 \text { to } \$ 228 \text { per } \\
\text { month }\end{array}$} & $\begin{array}{l}\text { - Done through family health } \\
\text { care teams }\end{array}$ \\
\hline & - About 240,000 CHAs & & & $\begin{array}{l}\text { - Teams consist of nurses and } \\
\text { physicians from the local clinics }\end{array}$ \\
\hline & - Launched in 1991 & & & - 33,000 family health care teams \\
\hline \multirow[t]{3}{*}{ Pakistan } & Lady Health Worker (LHWs) & \multirow{3}{*}{$\begin{array}{l}\text { Supporting maternal and child health } \\
\text { services, which include family planning, } \\
\text { HIV/AIDS and treatment of minor illnesses. } \\
\text { Providing health education, essential } \\
\text { drugs for minor ailments, contraceptives, } \\
\text { vaccination and making referrals }\end{array}$} & \multirow[t]{3}{*}{$\$ 343$ per year } & \multirow{3}{*}{$\begin{array}{l}\text { Conducted by Lady Health } \\
\text { Worker supervisor }\end{array}$} \\
\hline & - About 90,000 LHWs & & & \\
\hline & - Launched in 1992. & & & \\
\hline \multirow[t]{3}{*}{ Ethiopia } & $\begin{array}{l}\text { Health Extension Workers } \\
\text { (HEWs) }\end{array}$ & \multirow{3}{*}{$\begin{array}{l}\text { Providing basic first aid, contraceptives, } \\
\text { and immunizations, as well as diagnosing } \\
\text { and treating malaria, diarrhoea, and } \\
\text { intestinal parasites }\end{array}$} & \multirow[t]{3}{*}{ About $\$ 84$ monthly } & \multirow{3}{*}{$\begin{array}{l}\text { Conducted by district team } \\
\text { comprising health officer, a public } \\
\text { health nurse, an environmental } \\
\text { technician and health education } \\
\text { expert }\end{array}$} \\
\hline & - About 34,000 HEWs & & & \\
\hline & - Launched in 2003 & & & \\
\hline \multirow[t]{3}{*}{ India } & $\begin{array}{l}\text { Accredited Social Health } \\
\text { Activists (ASHAs) }\end{array}$ & \multirow{3}{*}{$\begin{array}{l}\text { Community mobilisation, motivating } \\
\text { women to give birth at health posts, } \\
\text { promoting immunisations, family } \\
\text { planning, treating basic illness, } \\
\text { keeping demographic records, } \\
\text { and improving village sanitation. }\end{array}$} & \multirow{3}{*}{$\begin{array}{l}\text { About } 600 \text { rupees }(\$ 10) \text { for } \\
\text { facilitating an institutional } \\
\text { delivery, and } 150 \text { rupees } \\
(\$ 2.50) \text { for each child that } \\
\text { successfully completes } \\
\text { immunisation session }\end{array}$} & \multirow[t]{3}{*}{ Conducted by ASHA facilitators } \\
\hline & - About 800,000 (ASHAs) & & & \\
\hline & - Launched in 2005 & & & \\
\hline
\end{tabular}

implementation of CBHW programmes [49]. Specifically, in 2010, the Global Health Workforce Alliance (GHWA) organised the Global Consultation on Community Health Workers, and recommended for the integration of CBHWs into national health systems. Part of this integration process was to include a regular and sustainable remuneration stipend for CBHWs. The GHWA, which is under WHO, is an innovative partnership aimed at coordinating solutions to the global health workforce crisis, and has a membership of over 400 organisations.

However, this pathway towards integration - the $\mathrm{HRH}$ crisis and its associated discourse - has been limited in a number of ways. In order to reach national scale, some countries have rapidly scaled up or deployed national CBHW programmes in a relatively short period of time. The Pakistan and Indian programmes, for example, deployed 90,000 and 462,000 CBHWs respectively over the last decade, while the Ethiopian HEW programme deployed 34,000 workers over a period of four years. This rapid scale-up of CBHW programmes generated several challenges in terms of quality and management of the programme [16,40,41,49-55]. These challenges were often due to insufficient and inconsistent programme funding, and inadequate programme logistics management. Further, the programmes were sometimes poorly planned which resulted in problems of sustainability in terms of both quality of care and retention of health workers. These problems resulted in a lack of continuity in the relationship between $\mathrm{CBHWs}$ and their communities, thereby affecting the acceptability and adoption of the CBHWs in population component of the health systems [6].

\section{Attributes of the intervention}

This section focuses on the pathway between attributes of the intervention (the national CBHW programme) and the integration process of the CBWHs in the health system.

\section{National community-based health workers' ability to deliver services}

Perceived relative advantage of national CBHWs' programmes in terms of service delivery over other similar programmes, such the traditional birth attendants, can positively influence the integration process. High quality service delivery may be triggered in situations where national CBHWs see their incentives as consistent, predictable, appropriate and fair in relation to their tasks, as well as where they have a reasonable workload, good training, and regular supervision from professional health workers $[2,6,19,34-36,44,46,47,56]$. These components can increase CBHWs' "willingness and ability to deliver services, which in turn can lead to better quality services and to improved health outcomes" [2], p 38. Good services and improved health outcomes may generate increased interest among actors in the adopting systems towards CBHWs, which can subsequently enhance acceptability and adoption of national CBHWs by the population. For instance, in Ethiopia "ninety three per cent of participants indicated that they would prefer 
HEWs to assist them during labour, rather than traditional birth attendants", as they perceived HEWs as being more knowledgeable [26], p 3.

This pathway - of good services or performance facilitating the integration process - may, however, be threatened in many ways. Limited availability and accessibility to supplies and medicines by CBHWs can affect service delivery $[16,41,49,52,57,58]$ and subsequently the acceptability and adoption of CBHWs within the population and health service delivery functions of the health systems. In Pakistan, limited access to drugs by LHWs for community activities "caused embarrassment and made Lady Health Workers suspect in the eyes of the community, because they were accused of selling drugs and contraceptives in the market" [51], p 5. In Ethiopia, inadequate facilities at some health posts for giving deliveries discouraged some women from using the services promoted and provided by HEWs $[41,42,58,59]$. In India, challenges at health posts made promoting of institutional births by the ASHAs less acceptable, such that their advice to women to go to the clinic proved unsound, and an ASHA risked "losing face in the community and people were less likely to trust her on other matters" [49], p 1610. In the community, their inability to always provide drugs "induced the community's nonconfidence on ASHAs" [60], p 9.

Failure by training programmes to adequately cover all relevant skills can affect CBHWs' ability to deliver services, and this can subsequently undermine their acceptability and adoption of the programme both by other health professionals and the population. In India, because of limited training for curative services, the ASHAs were more "identified as 'link workers' or facilitators for appropriate care and the community have less acceptance for their curative role. The ASHAs were less confident on their curative care skills" [60], p 9. In addition, effective service delivery by ASHAs was constrained by the incentive structure. The ASHAs could not perform some tasks as they were done at a net personal financial loss. Scott \& Shanker [49], p 1609 explain that the ASHAs complained that "by the time they are fully immunized, we have spent almost Rs. 500 [in transportation costs] on the child and we get only Rs. 150 as compensation". The ineffective, outcome-based payment structure also constrained ASHAs' work output [43], since some ASHAs tended to focus more on those activities which attract payment, such as provision of contraceptives and facility-based deliveries, at the expense of other essential activities such as general health promotion activities at community level $[6,43,49]$. However, there is also evidence that gender inequality and poverty made some of the ASHAs to see the post of a health worker as a path to 'liberation', and they willingly put in extra effort when conducting their duties, despite not receiving adequate remuneration [43].

\section{Adopting system}

In the third pathway, we analyse how and why the perspectives and participation of the actors in the adopting systems (e.g. politicians, decision makers, policy makers, other health workers, and community members) can influence the acceptability and adoption of national CBHW programmes into health systems.

A positive perspective by some politicians and community members in the adoption system towards national CBHW programmes, which may be triggered by their involvement in the programme, can facilitate integration. Full participation of actors in the adoption system can facilitate integration process as it can lead actors to view the CBHWs as "legitimate and credible, to have confidence in their knowledge and skills and to view their services as relevant and valuable. This in turn can lead to good relationships between CBHWs and recipients" [2], p 38.

\section{Perspectives by politicians and professional health workers}

In Ethiopia and Pakistan positive perspectives of national CBHW programme by politicians facilitated integrated governance and leadership resulting in common goals and standardised financial resources. The Prime Ministers in both countries spearheaded the launch of the programmes, thereby facilitating the integration process of CBHWs into national civil service structures $[17,42,45]$. For instance in Pakistan, Wazir et al. [17], p 2 explain that "it is heartening to see that the LHW programme received adequate political commitment, since 1994. There has been a wide recognition of the programme among the political arena and all government quarters. The financial and administrative support has continued without any interruption".

On the other hand, negative perspectives of national CBHWs by other health workers can also affect the integration process. Negative perspectives can be triggered by a lack of proper definition of CBHWs' tasks, such as in the cases of Brazil and Pakistan. In Brazil, "CHAs faced resistance to acceptance as from other health professionals (mainly nurses) - due to issues of liability, unclear roles, their ambiguous position in the entrenched physician/nurse-based hierarchy and overlap with work assigned to auxiliary nurses" [16], p 332. Physicians' perspectives and minimal opportunities to communicate directly with $\mathrm{CHAs}$ were the major challenges given by CHAs' regarding their integration within Family Health System teams [16]. In Pakistan, non-acceptance by the established professions was also cited as one of the issues which affected the integration process of Lady Health Workers into the health system [17]. 


\section{Community perspectives}

Positive perspectives of national CBHWs by community members, which may be triggered through recruitment of local people, can facilitate the integration process into the population. In Pakistan, "the hiring of local people contributed towards the high level of acceptability and trust that LHWs enjoyed in communities, as well as an increased community acceptance of several culturally sensitive issues like family planning" [51], p 3. Selection of local people in both India and Brazil also positively influenced the acceptability and adoption of national CBHW services. In Brazil, since they live in the community, CHAs were able to provide " 24 hours of basic health services to the community at the doorstep", a process which is greatly appreciated, "especially by women, who, for cultural reasons could not leave their houses" [16], p 339.

Apart from just the concept of recruiting local people, the sex of CBHWs also plays a role in influencing the integration process. Studies in Ethiopia attributed part of an increase in mothers' utilisation, acceptability and adoption of the services provided by HEWs to the recruitment of local females [50,61]. Female workers "were preferred for the premises of degree of closeness, easier disclosure of personal problems and as a matter of cultural norms. Associated with cultural norms and biological factors, mothers are ready to share their personal issues to females than to males" [61], p 6. In India, recruitment of local women as ASHAs helped in increasing use of modern contraceptives among women in the communities [38].

This pathway between positive perspectives by actors leading to enhanced integration may be undermined in many ways. First, integration may be affected if the community members that are selected as CBHWs or the structures or leaders that offer support to the CBHWs are regarded as poorly functioning or otherwise suspect [2]. This can affect integration as community members may not perceive the CBHW programme as credible or trustworthy. For example, in some instances, inadequate consultation between local leaders and community members in India resulted into the selection of ASHAs with limited community support $[49,60]$.

Further, cultural perspectives of gender, which include not supporting in particular young and unmarried women to walk and do the work, can also affect the integration process [50,17]. In Pakistan, "if one of the LHWs was married and the other unmarried, the married one provided respectable company and was better able to discuss family planning issues, a topic that was generally not acceptable for the unmarried worker to raise" [55], p 55. In addition, in some parts of Pakistan, "the LHWs found it difficult to talk to men about family planning" [2], p 27. The LHW's mobility, especially discussing with unrelated males on sensitive issues, led to a loss of status of women, as such a practice was considered as a sign of being uncultured $[39,55]$. Overall, acceptance of services can be limited due to gender discrimination. "Even though the program's focus is maternal and child health care, LHWs still have to face difficulties owing to traditional gender norms in many parts of the country" [17], p 5 .

Caste-based village hierarchies may also affect the integration process by restricting mobility of CBHWs. In Pakistan, the caste system discouraged visits by LHWs beyond the biradari (extended family) boundaries. Since most LHWs tended to be from lower castes, they preferentially visited co-members of their extended family who are likely to share similar socioeconomic circumstances, thereby resulting in other social classes not fully accessing the health services $[17,55,57]$. A study by Mumtaz et al. [55], p 54 confirmed that "the rejection of their services by higher caste women also discouraged LHWs from venturing to their homes". In India, the lower caste ASHAs were discriminated against by the higher class people, thereby affecting service delivery, as well as the acceptability and adoption of services within the affected areas [43].

Further, the receipt by CBHWs of monthly salaries may trigger mixed responses at community level, which in turn may affect the integration process. While the CBHWs may feel that "their incentives are appropriate, community members may question the motivation and credibility of CBHWs who are salaried rather than volunteers" [2], p 18. In India, the ASHAs were perceived as being entirely accountable to auxiliary nurse midwifes, especially since they collect their remuneration from the primary health centre [49].

\section{Health system characteristics}

Finally, we analyse the pathway between the health systems characteristics and integration of national CBHWs into health systems. Review of data suggests that integration of national CBHWs into existing structures may enhance programme compatibility with local practises, values and regulations. Compatibility with health systems characteristics can foster good relationships between CBHWs and other professional health workers, while also improving referral processes, information transfer, and general health service delivery. A combination of these components may enhance the pattern and extent of acceptability and adoption of national CBHWs by actors into the adopting system.

Examples of how integration in health systems characteristics can facilitate programme compatibility can be drawn from Brazil, Ethiopia and Pakistan. In Brazil, integration of the CHA programme within the municipal health council (responsible for allocating financial resources for health, which come from the federal and 
state governments) enhanced acceptability and adoption of the CHAs by the government officials, health service providers and other citizens. This process also guaranteed allocation of finance for primary health care to the $\mathrm{CHA}$ programme as well as acceptability and adoption of CHAs within the family health teams [16,34]. The integration of $\mathrm{CBHW}$ training components into Ministries of Health in Brazil and Ethiopia facilitated compatibility of training and certification of national CBHWs with those of institutions responsible for developing training curriculum, conducting training and certifying professional health workers $[3,16,34,37]$. In Pakistan, supervision is done by senior LHWs who are accountable to professional health workers $[17,37]$. Further, placing CBHWs in the civil structure in Brazil, Ethiopia and Pakistan facilitated provision of standardised monthly incentives which helped national CBHWs to deliver services, thereby positively contributing towards the integration process $[16,17,34,37,51]$. In India, integration of the ASHA programme into the ASHA mentoring group and National Health Services Resource Center helped to reduce resistance towards ASHAs from health workers as well as from community members. These institutions played a crucial role in taking various steps aimed at resolving the differences at the national level $[43,49,60]$.

The pathway that we propose, linking health systems characteristics and the integration of national CBHWs into health systems, may be challenged in a number of ways. For example, the existence of parallel or hierarchical communication structures can limit the integration process of national CBHWs into the functions of the health system, by affecting the smooth flow of information. In India, the hierarchical communication structure in place constrained information flow as well as any ability by the programme to address key health systems challenges [49]. The ASHAs, who at times tended to have far more understanding than many health professionals of the dynamics affecting the use of health services (for example, why many women choose not to give birth in the hospital despite their being offered incentives for institutional deliveries), could not effectively relay the message to the decision makers due rigid communication systems $[49,60]$. In Pakistan, studies have shown that "there is a management information system but it is not integrated with the overall health system, which leaves a vacuum in decision making because the problems and issues from the grass root level are not taken into consideration while making allocations, disbursements, procurements etc. [Although] there are good linkages at higher levels, at the field levels (i.e. basic health units and other areas), the linkages are poor due to inherent weaknesses in the health system itself" [17], p 4.

\section{Discussion}

Given that this systematic review was structured around five components - namely the nature of the problem, the intervention, the adoption system, the health system characteristics, and the broad context - the discussion is thus centred around these themes.

Several factors dictated the degree and nature of national $\mathrm{CBHW}$ programme integration into different countries' health systems. In Brazil, integration of the CHA programme into the municipal health councils facilitated compatibility of the programme with the governance, financial, and service delivery health systems functions. Similarly, in India, integration of the ASHAs programme into the National Health Services Resource Center helped in reducing conflicts between ASHAs and other actors in the health system. In Ethiopia and Pakistan, positive perspectives by politicians facilitated full integration of CBHWs into the civil service structure and Ministry of Health in general. Integration of the programme into the Ministries of Health in Brazil, Ethiopia and Pakistan, facilitated full integration of the training processes of the CBHWs by national training institutions. Further, in all the four countries, positive perspectives by some community members, which were triggered mainly though participatory processes, positively facilitated the integration process.

On the other hand, limited definition of tasks at health facility level in Brazil affected acceptability of CHAs by other health workers, thereby resulting into sub-optimal or partial integration into the human resources function of health system. Similarly, discrimination in Pakistan and India, based on social-cultural practices, gender, age and marital status affected the full integration process of CBHWs into the population as well as the health service delivery functions of the health system. In Ethiopia, limited service delivery affected integration of some of the services provided by HEWs within the population function of the health system. In India the hierarchical communication structure resulted into rigidity and top-down power which constrained information flow and subsequently affected the integration process of ASHAs.

In general, we found no instance when the national CBHW programmes are fully integrated into health systems. Instead, different aspects of the programmes are integrated in different ways, whether fully or partially into one or more functions of the health systems (Table 5). This 'mosaic' type of integration is indicative of a complex, multi-functional and dynamic process. For example, while some aspects of the CHA programme in Brazil are fully integrated into the governance and financial functions of the health system, other aspects are partially integrated into the human resources and health service delivery health systems functions. Similarly, while the incentive aspect of the LHW programme in Pakistan 
is fully integrated into the financial functions, other aspects of the programme are only partially integrated into the population, health service delivery, and human resources health systems functions, with the management information system being completely non-integrated. While the programme is fully integrated into some components of the health system in Ethiopia, it is only partially integrated in health service delivery. In India, the ASHAs are fully integrated in the goals and outcomes of the health system functions but only partially integrated in the other functions.

Based on the findings, we built on the original conceptual framework of integration of national CBHWs into health systems to include the specific factors which affect the integration process as reflected in Figure 3.

Studies on other health innovations have indicated that for integration to be successful, the adopting system or context should be motivated and competent, in terms of skills, resources, values, goals, regulations [22,62-64]. Limited capacity within a given context to adopt CBHWs can push the CBHWs to the margins of the health system, where they may occupy an ambiguous position as volunteers/workers. Lack of clarity in the CBHW position may result in CBHWs being expected to work regular hours and yet not having the employment rights of other health workers. This situation may affect health service delivery as well as programme sustainability, as CBHWs may feel unfairly treated [10].

On the other hand Schneider et al. [10], p 186 argue that "it is also not clear that the solution to the difficulties associated with CBHWs lies in incorporating them wholesale into the civil service". These authors suggest that placing all CBHWs within the civil services may limit the possibilities for more for inclusive participation. Second, this can also limit the expression of a range of different motivations or non-financial incentives such as clearly defining responsibilities, appropriate job aides, resources/supplies, and community connectedness [14,47,65-68]. Promoting community connectedness is vital as it is a cornerstone of the CBHW model [6,35]. Community connectedness is also relevant for the integration process as it may promote "a sense of relatedness with the local public health services, and thus accountability towards the system, a sense of credibility and legitimacy of being part of the local public health services, an anticipation of being valued by the local public health services as well as an assurance that there is a system for back-up support" [19], p 5. Putting more emphasis on placing CBHWs in the civil service structure as compared to promoting community connectedness may affect acceptability and adoption of national CBHWs at community level, since it may trigger mixed perspectives regarding motivation, credibility and accountability of CBHWs. Some people may perceive CBHWs as being too accountable to the Ministry of Health as opposed to the community, as was the case in India $[2,49]$.

Having successful national CBHW programmes is likely to require strategies that ensure the integration both at the community and formal health system levels. Further, to reduce the challenges related to planning and

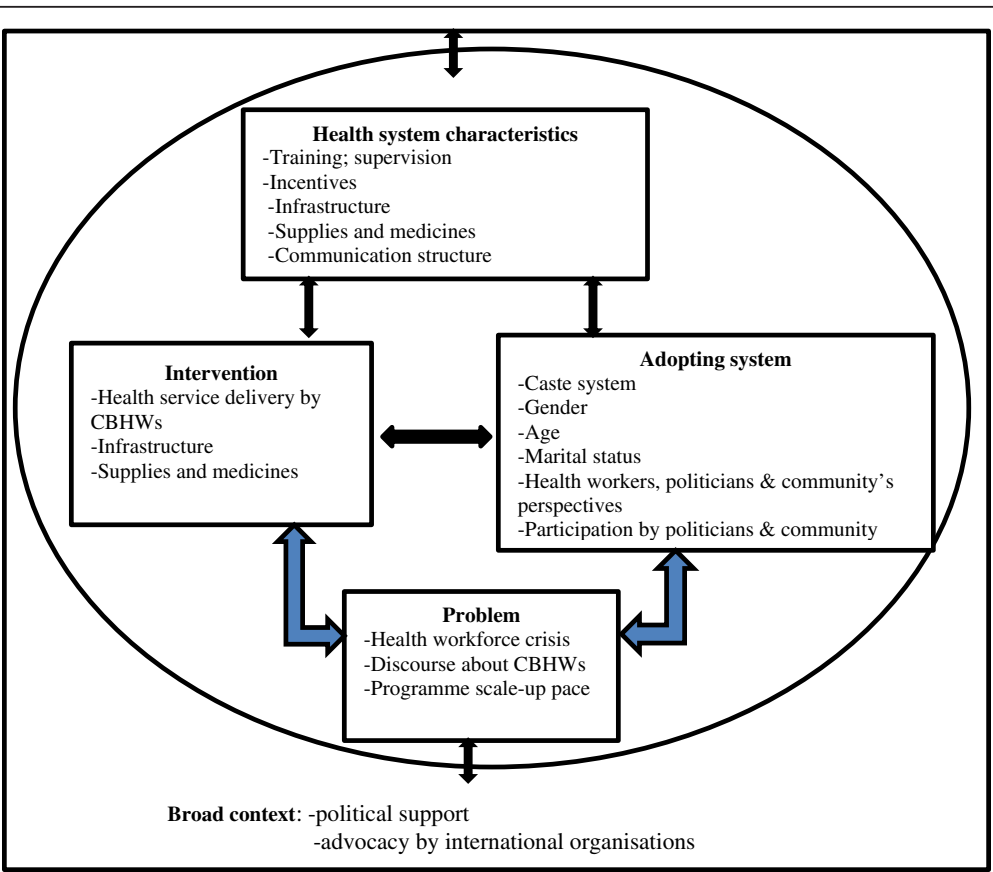

Figure 3 Factors influencing integration of national CBHWs in health systems. 
management as a result of rapid scale-up, it may be necessary for countries to adopt a stepwise approach during the integration process. Such an approach can provide sufficient space for drawing lessons to guide programme scale-up.

\section{Strengths and limitations}

One main strength of the study lies in the extensive search of the literature. The inclusion of papers utilising different methodological approaches, including mixedmethods papers and reviews, provided in-depth insights into factors influencing the integration of national CBHWs into health systems. The use of a multi-disciplinary team (with expertise in both public health and anthropology) in the review, and the synthesis of data, enriched the synthesis as it provided us with an opportunity to draw and collate team members' interpretations of the findings. However, one of the limitations of the review was the possibility of missing out some publications. We tried to mitigate this by conducting several searches between November 2013 and March 2014, and also searching the references of publications. The other limitation was the inclusion of only studies conducted in English as this is the main language with which the authors were conversant. However, the inclusion of systematic reviews helped us capture some of studies that we may have missed out due to language barriers, thereby helping us to develop a rich account of the factors influencing the integration of national CBHWs in LMICs.

\section{Conclusion}

Our findings indicate that different aspects of the national CBHW programmes are integrated in different ways within particular functions of the health systems. The acceptability and adoption of national CBHW programmes in health systems was shaped by the interaction between the perspectives of the actors within the adopting system, as well as the compatibility of CBHWs with the health systems characteristics and the broad context. Further the perspectives of the human resources for health gap by actors in the adopting system and within the broad context affected the integration process. Prior understanding of contextual factors that can impact integration process is critical for successful integration of national CBHW programmes into health systems. This suggests the need for having comprehensive approaches for providing baseline contextual data at the beginning of an integration process, about which stakeholders should be aware as they integrate $\mathrm{CBHW}$ programmes into the health systems. In addition, it is important to follow a stepwise approach to any national CBHW programme integration process in order to reduce some of the planning and managerial difficulties that can be associated with rapid scale-up and integration.

As they mature, CBHW programmes have the potential for contributing towards reducing the huge human resources for health gap and extending primary health care services to 'hard to reach' groups and areas if appropriate attention is given to their integration processes in the health systems. Considering that health systems are interconnected, dynamic and complex in nature, and that they consist of independent agents whose behaviour is based on physical, psychological and social rules, the use of other research frameworks which acknowledge health systems as complex and adaptive systems would help provide additional insights on this subject.

\section{Abbreviations}

ASHA: Accredited social health activist; CBHW: Community based health worker; CHA: Community health agent; HEW: Health extension worker; LHW: Lady Health worker.

\section{Competing interests}

The authors declare that they have no competing interests.

\section{Authors' contributions}

All four authors contributed towards the study design, review of data, analysis and synthesis. JMZ drafted the manuscript and all authors contributed towards revision of the manuscript. All authors read and approved the final manuscript.

\section{Acknowledgments}

This paper is part of a $\mathrm{PhD}$ project on Integrating Community Health Assistants in the Health System in Zambia. The work was supported by the Umeå Centre for Global Health Research, funded by FAS, the Swedish Council for Working Life and Social Research (Grant no. 2006-1512), the Swedish Centre Party Donation for Global Research Collaboration, the Swedish Research School for Global Health, the Southern Africa Consortium for Research Excellence (SACORE), and the African Doctoral Dissertation Research Fellowship offered by the African Population and Health Research Centre (APHRC) in partnership with the International Development Research Centre (IDRC). We would also like to acknowledge the technical input from Rakhal Gaitonde.

Received: 12 June 2014 Accepted: 15 September 2014

Published: 22 September 2014

\section{References}

1. WHO: Treat, Train, Retain - The AIDS and Health Workforce Plan. Geneva: Report on the Consultation on AIDS and Human Resources for Health; 2006.

2. Glenton C, Colvin CJ, Carlsen B, Swartz A, Lewin S, Noyes J, Rashidian A: Barriers and facilitators to the implementation of lay health worker programmes to improve access to maternal and child health: qualitative evidence synthesis. Cochrane Database Syst Rev 2013, (10): Art. No.: CD010414. doi:10.1002/14651858.CD010414.pub2.

3. Perry HB, Zulliger $R$, Rogers MM: Community health workers in low-, middle-, and high-income countries: an overview of their history, recent evolution, and current effectiveness. Annu Rev Public Health 2014, 18(35):399-421.

4. GHWA WHO: Catalyst for Change, The Global Health Workforce Alliance 2009 Annual Report. Geneva: WHO; 2009-2010.

5. Zulu JM, Kinsman J, Michelo C, Hurtig AK: Developing the national community health assistant strategy in Zambia: a policy analysis. Health Res Policy Syst 2013, 11:24.

6. Liu A, Sullivan S, Khan M, Sachs S, Singh P: Community health workers in global health: scale and scalability. Mt Sinai J Med 2011, 78(3):419-435.

7. Walt G: Community Health Workers in National Programmes: Just another Pair of Hands? Milton Keynes, UK: Open University Press; 1990. 
8. WHO, UNICEF: Declaration of Alma-Ata; Adopted at the Int. Conf. Primary Health Care, Sept. 6-12, Alma-Ata, USSR. 1978. http://www.who.int/publications/almaata_declaration_en.pdf.

9. Abbatt F: Scaling up Health and Education Workers: Community Health Workers. Literature Review. London: Department for International Development, Health Systems Resource Centre; 2005.

10. Schneider $H$, Hlophe $H$, van Rensburg D: Community health workers and the response to HIV/AIDS in South Africa: tensions and prospects. Health Policy Plan 2008, 23:179-187.

11. Lehmann U, Sanders D: Community Health Workers: What Do We Know About Them?. Geneva: WHO; 2007

12. Hanefeld J, Musheke M: What impact do global health initiatives have on human resources for antiretroviral treatment roll-out? A qualitative policy analysis of implementation processes in Zambia. Hum Res Health 2009, 7:8

13. Hadley M, Maher D: Community involvement in tuberculosis control: lessons from other health care programmes. Int J Tuberc Lung Dis 2000, 4(5):401-408.

14. Bhutta ZA, Pariyo G, Huicho L: Global Experience of Community Health Workers for Delivery of Health -Related Millennium Development Goals: A Systematic Review, Country Case Studies, and Recommendations for Integration into National Health Systems. Geneva: WHO/ Global Health Workforce Alliance; 2010.

15. Singh P: One Million Community Health Workers; Global Technical Taskforce report; 2013.http://1 millionhealthworkers.org/files/2013/01/1 mCHW TechnicalTaskForceReport.pdf. (accessed 1 May, 2014).

16. Zanchetta MS, McCrae Vander Voet S, Galhego-Garcia W, Smolentzov VMN, Talbot Y, Riutort M, Galhego AMMF, de Souza TJ, Caldas RS, Costa E, Kamikihara MM, Smolentzov S: Effectiveness of community health agents' actions in situations of social vulnerability. Health Educ Res 2009, 24(2):330-342.

17. Wazir MS, Shaikh BT, Ashfaq Ahmed A: National program for family planning and primary health care Pakistan: a SWOT analysis. Reprod Health 2013, 10:60

18. Callaghan M, Ford N, Schneider H: A systematic review of task shifting for HIV treatment and care in Africa. Hum Res Health 2010, 8:8.

19. Kane SS, Gerretsen B, Scherpbier R, Dal Poz M, Dieleman M: A realist synthesis of randomised control trials involving use of community health workers for delivering child health interventions in low and middle income countries. BMC Health Serv Res 2010, 10:286.

20. Lewin S, Munabi-Babigumira S, Glenton C, Daniels K, Bosch-Capblanch X, van Wyk BE, Odgaard-Jensen J, Johansen M, Aja GN, Zwarenstein M, Scheel IB: Lay health workers in primary and community health care for maternal and child health and the management of infectious diseases. Cochrane Database Syst Rev 2010, (3): Art. No.: CD004015. doi:10.1002/ 14651858.CD004015.pub3.

21. Gilmore B, McAuliffe E: Effectiveness of community health workers delivering preventive interventions for maternal and child health in low- and middleincome countries: a systematic review. BMC Public Health 2013, 13:847.

22. Atun R, De Jongh T, Secci F, Ohiri K, Adeyi O: Integration of targeted health interventions into health systems: a conceptual framework for analysis. Health Policy Plan 2010, 25:104-111.

23. Atun RA, Menabde N: Health systems and systems thinking. In Health Systems and Communicable Disease Control. Edited by Coker R, Atun RA, Mckee M. Buckingham: Open University Press; 2008.

24. van Olmen J, Criel B, Van Damme W, Marchal B, Van Belle S, Van Dormael M, Hoerée T, Pirard M, Kegels G: Analyzing Health Systems To Make Them Stronger, Studies in Health Services Organisation \& Policy. Antwerp: ITGPress; 2010.

25. Rogers E: Diffusion of Innovations. New York: The Free Place; 1995.

26. Negusse $H$, McAuliffe $E$, MacLachlan M: Initial community perspectives on the Health Service Extension Programme in Welkait, Ethiopia. Hum Res Health 2007, 5:21.

27. van der Knaap LM, Leeuw FL, Bogaerts S, Nijssen LTJ: Combining Campbell standards and the realist evaluation approach. Am J Eval 2008, 29(1):48-57

28. Petrosino A, Boruch RF, Soydan H, Duggan L, Sanchez-Meca J: Meeting the challenges of evidence based policy: the Campbell collaboration. Ann Am Acad Pol Soc Sci 2001, 578:14-34.

29. Moher D, Liberati A, Tetzlaff J, Altman DG, The PG: Preferred reporting items for systematic reviews and meta-analyses: the PRISMA statement PLoS Med 2009, 6(7):e1000097.

30. Critical Appraisal Skills Programme (CASP): Qualitative Appraisal Checklist for Qualitative Research; Available fromhttp://www.casp-uk.net/wp-content/ uploads/2011/11/CASP' Qualitative 'Appraisal 'Checklist'14oct10.pdf 2006.
31. Munro S, Lewin S, Smith H, Engel M, Fretheim A, Volmink J: Adherence to tuberculosis treatment: a qualitative systematic review of stakeholder perceptions. PLoS Med 2007, 4(7):e238.

32. Braun V, Clarke V, Braun V, Clarke V: Using thematic analysis in psychology. Qual Res Psychol 2006, 3:77-101

33. Noyes J, Lewin S: Chapter 6: supplemental guidance on selecting a method of qualitative evidence synthesis, and integrating qualitative evidence with Cochrane intervention reviews. In Supplementary Guidance for Inclusion of Qualitative Research in Cochrane Systematic Reviews of Interventions, Volume 1. Edited by Noyes J, Booth A, Hannes K, Harden A, Harris J, Lewin S, Lockwood C, Cochrane Collaboration Qualitative Methods Group. ; 2011.

34. Celletti F, Wright A, Palen J, Frehywot S, Markus A, Greenberg A, de Aguiar RA, Campos F, Buch E, Samb B: Can the deployment of community health workers for the delivery of HIV services represent an effective and sustainable response to health workforce shortages? Results of a multicountry study. AIDS 2010, 24(suppl 1):S45-S57.

35. Macinko J, Marinho de Souza Mde F, Guanais FC, da Silva Simões CC: Going to scale with community-based primary care: an analysis of the family health program and infant mortality in Brazil, 1999-2004. Soc Sci Med 2007, 65:2070-2080.

36. Aquino R, de Oliveira NF, Barreto ML: Impact of the family health program on infant mortality in Brazilian municipalities. Am J Public Health 2009, 99(1):87-93.

37. Hafeez A, Mohamud BK, Shiekh MR, Shah SA, Jooma R: Lady health workers programme in Pakistan: challenges, achievements and the way forward. J Pak Med Assoc 2011, 61(3):210-215.

38. Douthwaite $M$, Ward $P$ : Increasing contraceptive use in rural Pakistan: an evaluation of the Lady Health Worker Programme. Health Policy Plan 2005, 20(2):117-23.

39. Haq Z, Hafeez A: Knowledge and communication needs assessment of community health workers in a developing country: a qualitative study. Hum Res Health 2009, 7:59.

40. Girma S, Yohannes AG, Kitaw Y, Ye-Ebiyo Y, Seyoum A, Desta H, Teklehaimanot A: Human resource development for health in Ethiopia: challenges of achieving the millennium development Goals. Ethiop J Health Dev 2007, 21(3):216-231.

41. Teklehaimanot A, Kitaw Y, Girma S, Seyoum S, Desta S, Ye-Ebiyo Y: Study of the working conditions of health extension workers in Ethiopia. Ethiop J Health Dev 2007, 21(3):246-259.

42. Teklehaimanot HD, Teklehaimanot A: Human resource development for a community-based health extension program: a case study from Ethiopia. Hum Res Health 2013, 11:39.

43. Kumar S, Kaushik A, Kansal S: Factors influencing the work performance of ASHA under NRHM - A cross sectional study from eastern India. Indian J community health 2012, 24:4

44. Hermann K, Van Damme W, Pariyo GW, Schouten E, Assefa Y, Cirera A, Massavon W: Community health workers for ART in sub-Saharan Africa: learning from experience - capitalizing on new opportunities. Hum Res Health 2009, 7:31.

45. Balabanova D, Mills A, Conteh L, Akkazieva B, Banteyerga H, Dash U, Gilson L, Harmer A, Ibraimova A, Islam Z, Kidanu A, Koehlmoos TP, Limwattananon S, Muraleedharan VR, Murzalieva G, Palafox B, Panichkriangkrai W, Patcharanarumol W, Penn-Kekana L, Powell-Jackson T, Tangcharoensathien $\checkmark$, McKee M: Good Health at Low Cost 25 years on: lessons for the future of health systems strengthening. Lancet 2013, 381(9883):2118-33.

46. Svitone EC, Garfield R, Vasconcelos MI, Craveiro VA: Primary health care lessons from the Northeast of Brazil: the Agentes de Saúde Program. Rev Panam Salud Publica 2000, 7:5.

47. Admassie A, Abebaw D, Woldemichael A: Impact evaluation of the Ethiopian health services extension programme. J Dev Effectiveness 2009, 1:430-449.

48. Wouters E, Van Damme W, van Rensburg D, Masquillier C, Meulemans $\mathrm{H}$ : Impact of community-based support services on antiretroviral treatment programme delivery and outcomes in resource-limited countries: a synthetic review. BMC Health Serv Res 2012, 12:194.

49. Scott K, Shanker S: Tying their hands? Institutional obstacles to the success of the ASHA community health worker programme in rural north India. AIDS Care 2010, 22(Suppl 2):1606-12.

50. Afsar HA, Qureshi AF, Younus M, Gul A, Mahmood A: Factors effecting unsuccessful referrals by the lady health workers in Karachi Pakistan. J Pak Med Asso 2003, 53:521-8.

51. Afsar HA, Younus M: Recommendations to strengthen the role of lady health workers in the national program for family planning and primary. J Ayub Med Coll Abbottabad 2005, 17(1):48-53. 
52. Koblinsky M, Tain F, Gaym A, Karim A, Carnell M, Tesfaye S: Responding to the maternal health care challenge: the Ethiopian health extension program. Ethiop J Health Dev 2010, 24(1):105-109.

53. Damtew ZA, Moges AS, Kaasb J: Revisiting the quality of Health Extension Workers' training: case study from Amhara Region, Ethiopia. Ethiop J Health Dev 2011, 25(3):201-205.

54. Shrivastava SR, Shrivastava PS: Evaluation of trained Accredited Social Health Activist (ASHA) workers regarding their knowledge, attitude and practices about child health. Rural Remote Health 2012, 12:2099.

55. Mumtaz Z, Salway S, Nykiforuk C, Bhatti A, Ataullahjan A, Ayyalasomayajula B: The role of social geography on Lady Health Workers' mobility and effectiveness in Pakistan. Soc Sci Med 2013, 91:48e57.

56. Jaskiewicz W, Tulenko K: Increasing community health worker productivity and effectiveness: a review of the influence of the work environment. Hum Res Health 2012, 10:38.

57. Haq Z, lqbal Z, Rahman A: Job stress among community health workers: a multi-method study from Pakistan. Int J Ment Health Syst 2008, 2(1):15.

58. Medhanyie A, Spigt M, Kifle Y, Schaay N, Sanders D, Blanco R, GeertJan D, Berhane $Y$ : The role of health extension workers in improving utilization of maternal health services in rural areas in Ethiopia: a cross sectional study. BMC Health Serv Res 2012, 12:352.

59. Medhanyie A, Spigt M, Dinant G, Blanco R: Knowledge and performance of the Ethiopian health extension workers on antenatal and delivery care: a cross-sectional study. Hum Res Health 2012, 10:44.

60. Gopalan SS, Mohanty S, Das A: Assessing community health workers' performance motivation: a mixed-methods approach on India's Accredited Social Health Activists (ASHA) programme. BMJ Open 2012, 2:e001557.

61. Birhanu Z, Godesso A, Kebede Y, Gerbaba M: Mothers' experiences and satisfactions with health extension program in Jimma zone Ethiopia: a cross sectional study. BMC Health Serv Res 2013, 13:74.

62. Greenhalgh T, Robert G, Macfarlane F, Bate P, Kyriakidou O: Diffusion of innovations in service organizations: systematic review and recommendations. Milbank Q 2004, 82(4):581-629.

63. Yetton P, Sharma R, Southon G: Successful IS innovation: the contingent contributions of innovation characteristics and implementation process. $J$ Inform Technol 1999, 14(1):53-68.

64. Wejnert B: Integrating models of diffusion of innovations: a conceptual framework. Annu Revf Sociol 2002, 28:297-326.

65. Peres EM, Andrade AM, Dal Poz MR, Grande NR: The practice of physicians and nurses in the Brazilian Family Health Programme-evidences of change in the delivery health care model. Hum Res Health 2006, 4:25.

66. Yared A: Non-Financial Incentives for Voluntary Community Health Workers: A Qualitative Study. Working Paper No. 1. Addis Ababa, Ethiopia: The Last Ten Kilometers Project, JSI Research \& Training Institute, Inc; 2009.

67. Zulu JM, Kinsman J, Michelo C, Hurtig AK: Hope and despair: community health assistants' experiences of working in a rural district in Zambia. Hum Res Health 2014, 12:30.

68. Rosenthal EL, Macinko J: JACM special issue on community health workers and community health workers practice. J Ambul Care 2011, 34(3):208-209.

doi:10.1186/1471-2458-14-987

Cite this article as: Zulu et al:: Integrating national community-based health worker programmes into health systems: a systematic review identifying lessons learned from low-and middle-income countries. BMC Public Health 2014 14:987.

\section{Submit your next manuscript to BioMed Central and take full advantage of:}

- Convenient online submission

- Thorough peer review

- No space constraints or color figure charges

- Immediate publication on acceptance

- Inclusion in PubMed, CAS, Scopus and Google Scholar

- Research which is freely available for redistribution 